\title{
VARIAÇÃO DO pH, ACIDEZ TITULÁVEL E DA MICROBIOTA DO LEITE DE VACA TRATADO EM FORNO MICROONDAS
}

\section{VALÉRIA RAMOS DA CRUZ Nutricionista}

Orientador: Prof. Dr.Antônio Joaquim de Oliveira

Dissertação apresentada à Escola Superior de Agricultura "Luis de Queiroz", da Universidade de São Paulo, para obtenção de título de Mestre em Ciências. Área de Concentração: Ciência e Tecnologia de Alimentos.

Piracicaba

Estado de São Paulo - Brasil

Novembro - 1996 


\section{Dados Internacionais de Catalogação na Publicação (CIP) DIVISÃo DE BIBLIOTECA E DOCUMENTAÇÃO - Campus "Luiz de Queiroz"/USP}

\section{Cruz, Valéria Ramos da}

Variação do $\mathrm{pH}$ acidez titulável e da microbiota do leite de vaca tratado em forno microondas / Valéria Ramos da Cruz. - - Piracicaba. 1996.

43 p. : il.

Dissertação (mestrado) - - Escola Superior de Agricultura Luiz de Queiroz, 1996. Bibliografia.

1. Leite - Microbiologia 2. Microonda em alimento 3. Microrganismo em leite Tratamento térmico I. Título 


\section{VARIAÇÃO DO pH, ACIDEZ TITULÁVEL E DA MICROBIOTA DO LEITE DE VACA TRATADO EM FORNO MICROONDAS}

\section{VALÉRIA RAMOS DA CRUZ}

Aprovada em 19.12.96

Comissão Julgadora:

Prof. Dr. Antônio Joaquim de Oliveira

ESALQ/USP

Prof. Dr. Gustavo Brasil Caruso

ESALQ/USP

Prof ${ }^{a}$. Dr ${ }^{a}$.Tais Helena Martins Lacerda

UNIMEP

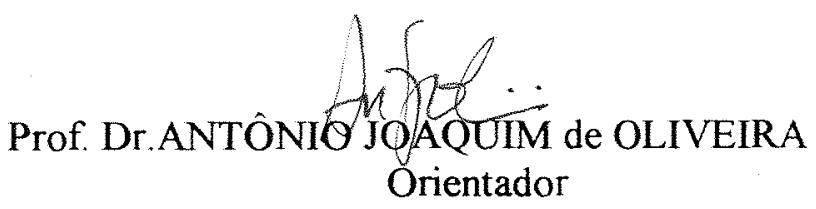


Aos meus avós

José e Emília

Raimundo e Maria José

DEDICO

Aos meus pais

Hélio e Enide

Aos meus irmãos

Fábio, Sérgio e Ricardo

Ao meu marido

Roggero

AGRADECO

$\grave{A}$ Deus

OFERECO 


\section{AGRADECIMENTOS}

- Ao Prof. Antônio Joaquim de Oliveira, meu mestre e grande incentivador, pelo carinho, dedicação e amizade tão sincera em todo o convívio acadêmico;

- À Escola Superior de Agricultura "Luiz de Queiroz", em especial ao Departamento de Ciência e Tecnologia Agroindustrial, seus professores e funcionários, pelos ensinamentos e pelo auxilio na realização deste trabalho;

- Ao Conselho Nacional de Desenvolvimento Científico e Tecnológico, pela concessão da bolsa de estudo;

- Aos amigos Cleomar Maria de Carvalho, Carlos Eduardo Garcia e Adriana Furlan Martins, pela força nos momentos de maiores dificuldades no laboratório;

- À Regina Lúcia de Mello Lourenço, tão grande amiga, que sempre acreditou e participou de meus projetos;

- Às bibliotecárias, Beatriz Helena Giongo e Midian Gustinelli, que sempre estiveram tão prontas a ajudar e que o fizeram desde o início do nosso convivio;

- À professora e grande amiga, Sônia Maria DeStefano Piedade, pelas análises estatísticas e pelo apoio nos momentos mais necessários;

- Aos meus amigos de turma, pela amizade e experiências vividas, que sempre serão lembradas;

- Ả Roggero e Marlene Chiarinelli, pelo carinho e atenção de que me cercaram em todas as etapas do meu convivio acadêmico;

- À minha família que, além de me proporcionar condições, confiou e apoiou todos os meus passos na minha vida acadêmica e profissional;

- À Deus, por encher meu coração de amor à minha profissão e à realização deste trabalho. 


\section{ÍNDICE}

Pág.

LISTA DE FIGURAS …......................................................... vi

LISTA DE APÊNDICE ........................................................ vii

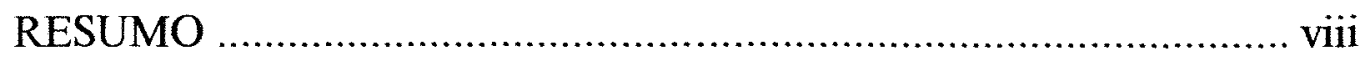

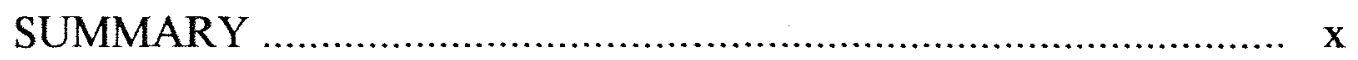

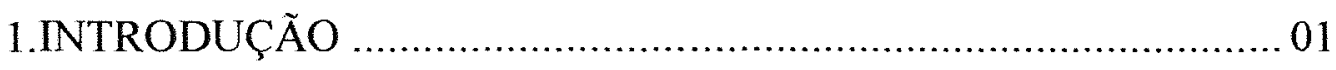

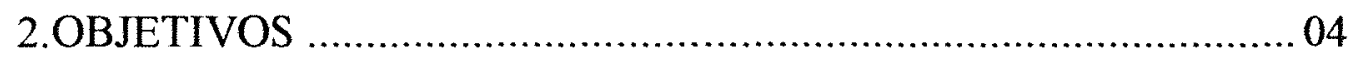

3. REVISÃO BIBLIOGRÁFICA _................................................. 05

3.1. O microondas e a qualidade química do leite ......................... 08

3.2. O microondas e a qualidade microbiológica do leite ................09

3.3. O tratamento do leite por microondas ............................... 13

4. MATERIAL E MÉTODOS ….................................................. 21

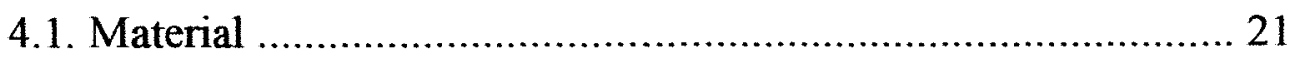

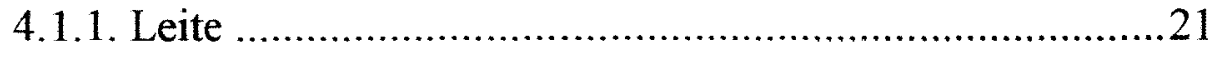

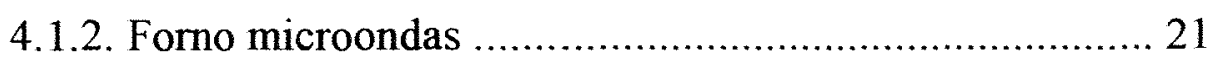

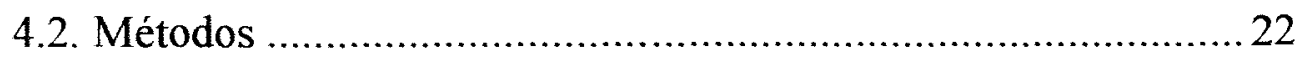

4.2.1. Amostragem do leite crú ........................................... 22

4.2.2. Tratamento do leite em forno de microondas caseiro .....22 


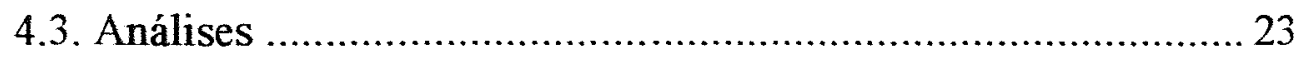

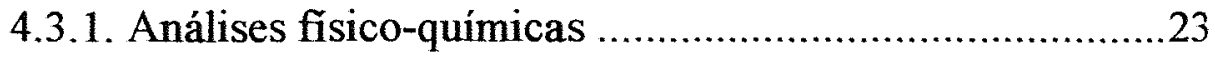

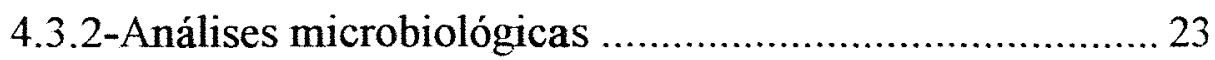

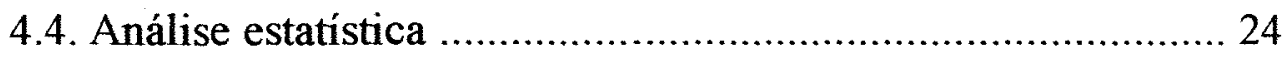

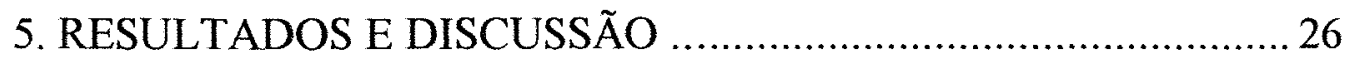

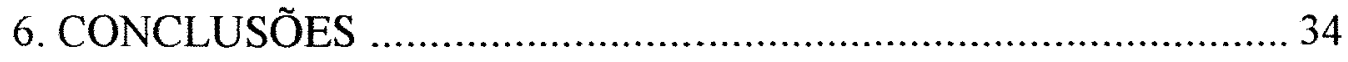

REFERÊNCIAS BIBLIOGRÁFICAS …....................................... 36 


\section{LISTA DE FIGURAS}

Pág.

Figura 1. Ação das microondas sobre o pH do leite de vaca

Figura 2. Ação das microondas sobre a acidez do leite de vaca 28

Figura 3. Ação das microondas sobre o número total de bactérias do leite de vaca

Figura 4. Ação das microondas sobre o número total de coliformes do leite de

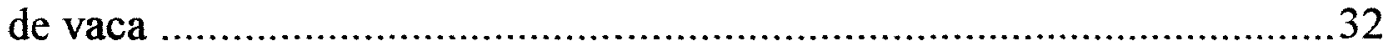




\section{LISTA DE APÊNDICES}

Pág.

Tabela 1. Composição do meio seletivo Bacto Violet Bile Agar (VRBA-DIFCO) para determinação de bactérias coliformes em produtos lácteos, conforme 0 "Standard Methods for the Examination of Dairy Products" ... 40

Tabela 2. Composição do meio PCA para determinação do número total de bactérias em produtos lácteos, conforme o "Standard Methods for the Examination of Dairy Products"

Tabela 3. Variação do pH do leite de vaca submetido à ação de microondas

Tabela 4. Variação da acidez do leite de vaca submetido à ação de microondas ....41

Tabela 5. Variação do número total de bactérias do leite de vaca submetido à ação de microondas

Tabela 6. Variação do número de coliformes do leite de vaca submetido à ação de microondas

Tabela 7. Variação da temperatura nos diferentes tempos e intervalos de tratamento 


\title{
VARIAÇÃO DO pH, ACIDEZ TITULÁVEL E DA MICROBIOTA DO LEITE DE VACA TRATADO EM FORNO MICROONDAS
}

\author{
Autora: Valéria Ramos da Cruz \\ Orientador: Prof. Antônio Joaquim de Oliveira
}

RESUMO

Neste trabalho procurou-se avaliar a eficácia da utilização de microondas para a inativação dos microrganismos presentes no leite de vaca cru, para assim alcançar segurança microbiológica, do ponto de vista de saúde pública.

Para tal, um volume de $1000 \mathrm{ml}$ de leite de vaca cru foi submetido à ação das microondas em forno caseiro, à potência máxima de $700 \mathrm{~W}$ e freqüência de $2450 \mathrm{Mhz}$ por 3 diferentes tempos: 5, 10 e 15 minutos. Após cada tempo estipulado, amostras de cerca de $40 \mathrm{ml}$ foram retiradas e resfriadas em banho de gelo, para posterior avaliação. Foram feitas as análises microbiológicas, contagem de bactérias e coliformes totais, e análises físico-químicas, $\mathrm{pH}$ e acidez. Para bactérias totais as amostras foram semeadas em meio de cultivo Agar de Contagem Total (PCA) e incubadas a $35,0 \pm 1^{\circ} \mathrm{C}$ por 48 horas. Para coliformes totais utilizouse o meio de cultivo Violeta Bile Agar Vermelho (VRBA), sob as mesmas condições. A contagem de colônias desenvolvidas foi feita em contador de colônias tipo Quebec.

A análise estatística dos dados demonstrou um efeito significativo $(p \leq 0,01)$ dos 3 tempos de exposição às microondas sobre a redução da contagem total de bactérias.

Quanto à contagem de coliformes, a análise estatística tornou-se desnecessária já que, após o plaqueamento das amostras dos tratamentos de 10 e 15 minutos em meio específico, não se observou o desenvolvimento de colônias 
microbianas. Já o tratamento por 5 minutos mostrou-se inadequado, uma vez que permitiu a sobrevivência destes microrganismos.

Embora as variações para $\mathrm{pH}$ e acidez tenham apresentado significância estatística, estas não são consideradas de importância para a estabilidade fisico-química ou propriedades organolépticas do leite.

Assim sendo, os resultados encontrados mostram que, sob as condições do presente trabalho, o tratamento do leite de vaca ao microondas caseiro por 10 minutos é adequado para reduzir a população bacteriana total e coliformes totais, provocando portanto, efeito semelhante àquele da pasteurização convencional do leite. 


\section{TITRATABLE ACIDITY, pH AND MICROBIOTE VARIATION OF COW'S MILK SUBMITED TO MICROWAVE OVEN TREATMENT}

Author: Valéria Ramos da Cruz

Adviser: Prof. Antônio Joaquim de Oliveira

\section{SUMMARY}

This report evaluates the efficiency of the use of microwave oven in inactivation of microorganisms present in raw cow's milk, in order to ensure microbiological safety in public health.

For that, $1000 \mathrm{ml}$ of raw cow's milk was put under the action of a household microwave oven, at $700 \mathrm{~W}$ and a frequency of $2450 \mathrm{Mhz}$ for 3 different periods: 5, 10 and 15 minutes. After each period, $40 \mathrm{ml}$ samples were cooled in an ice bath, for further evaluation. Microbiological analysis, such as total bacteria and coliformes, and physical chemical analysis, $\mathrm{pH}$ and titratable acidity were made. For total bacteria, samples were plated in Plat Count Agar (PCA) and incubated at 35,0 $\pm 1{ }^{\circ} \mathrm{C}$ for 48 hours, and for total coliforms couting, samples were plated on Violet Red Bile Agar (VRBA) and incubadet at same conditions. Counting of developed colonies was done on colonies counting type Quebec.

The statistichal analysis of data showed a significant effect $(p \leq 0,01)$ of the 3 periods of exposion to microwaves on the reducion of the total number of bacterias.

Regarding to total coliforms, statistichal analysis was not necessary since, the samples treated for 10 and 15 minutes, after plated in approprite culture media and incubation conditions, didn't developed any colonie. However, the 5 minute treatment was inadequate, since it allowed the survival of these microorganisms. 
Although the changes in $\mathrm{pH}$ and acidity were significant, they were not considered important for physical and chemical stability or organoleptics properties of the milk.

Therefore, the results found show that, under the actual conditions, the treatment of raw cow's milk in household microwave oven for 10 minutes is sufficient to reduce the total bacteria count as well as total coliforms, to the same level as conventional milk pasteurization. 


\section{INTRODUÇÃo}

O leite de vaca é considerado um alimento de alto valor biológico, apresentando elevada atividade de água e alta concentração de minerais (principalmente cálcio e fósforo), é rico em aminoácidos e assim é um excelente substrato para microrganismos.

Sabe-se da necessidade em se proceder tratamento térmico do leite de vaca cru para o consumo humano, independente da forma em que este será empregado, e a falta de cuidados para com sua segurança microbiológica poderá levar a casos de infeç̧ões gastrointestinais graves. A pasteurização do leite é capaz de minimizar este problema, inativando microrganismos patogênicos, não formadores de esporos, conhecidos por serem transmitidos através do leite. Além do mais, o tratamento térmico do leite lhe assegurará um maior tempo de conservação.

Já há alguns anos vem se estudando a utilização de microondas para a inativação de microrganismos do leite com tempos de tratamento extraordinariamente curtos.

É de grande importância que o tempo e a temperatura de exposição sejam adequados para que as microondas sejam letais aos microrganismos alvos. É bastante claro que o calor e as ondas eletromagnéticas apresentam efeitos fortemente interdependentes.

Enquanto o consumo de leite pasteurizado é requerido e já que o forno microondas é considerado um equipamento caseiro para pasteurização do 
leite, um método confiável deve ser desenvolvido. O método doméstico deve ser especifico, devendo ser observados os seguintes parâmetros: volume e temperatura inicial do leite, voltagem ou potência do forno microondas, tipo de utensílio para o aquecimento, tipo de exposição às microondas, manipulação do leite aquecido (mistura e resfriamento), temperatura mínima após o aquecimento e a efetiva composição do leite, já que algumas donas de casa retiram a nata do leite crú. Quando o procedimento for desenvolvido dentro destes parâmetros especificos e os riscos de doenças transmitidas pelo leite forem eliminados, então o tratamento do leite por microondas será eficiente.

A irradiação de microondas pode facilitar o aumento da vida útil de vários produtos, além do leite. Esta técnica, se adaptada ao uso comercial, poderá resultar em uma economia considerável de energia

A literatura discute o fato de existirem relativamente poucos sucessos nas aplicações de microondas no processamento de alimentos. Algumas razões para isto são o elevado capital e os custos operacionais, a vida curta e imprevisível dos magnetrons (o componente que converte energia elétrica em microondas) e dos outros utensílios eletrônicos que compõem o equipamento, além das oportunidades do mercado mal interpretadas e das vantagens dos métodos convencionais de aquecimento. Outros autores sugerem a falta de entendimento por parte dos fornecedores e usuários do equipamento, inexperiência interdisciplinar dos tecnologistas de microondas e dos tecnologistas de alimentos, e a carência de plantas pilotos adequadamente flexíveis disponíveis para pesquisas e desenvolvimento de produtos. Um entendimento incompleto com relação às propriedades elétricas e as características das microondas na tecnologia de alimentos também tem sido relatado como o problema principal para a aplicação industrial de microondas (YOUNG e JOLLY, 1990).

Há limitações para a comparação de métodos convencionais com o uso de microondas em relação à sobrevivência de microrganismos devido às 
condições utilizadas serem bastante diferentes, sendo que o uso de microondas em comparação com os métodos convencionais resultará em aquecimento mais uniforme e destruição das bactérias com maior eficiência. 


\section{OBJETIVOS}

O presente trabalho teve como objetivo tratar o leite de vaca em forno de microondas caseiro, buscando encontrar um tempo que assegurasse a destruição dos microrganismos presentes, sem alterar suas características físicoquímicas. 


\section{REVISÃO BIBLIOGRÁFICA}

Segundo a SAA- Secretaria de Agricultura e Abastecimento (1994), a contagem total de microrganismos no leite crú obtido sob condições higienicamente satisfatórias não deve exceder $5 \times 10^{5}$ cels $/ \mathrm{ml}$. Um requerimento essencial do leite tratado termicamente é a pequena e até insignificante possibilidade de sobrevivência e crescimento de organismos patogênicos (CALVO e OLANO, 1992). O leite crú está envolvido em uma importante fonte de infecção através de agentes bacterianos comumente associados a gastroenterites incluindo Salmonella spp, Campylobacter jejuni e Yersinia enterocolítica, além de apresentar-se como um veículo para a transmissão de outros patógenos importantes como Listeria monocytogenes e E.coli (THOMPSON e THOMPSON, 1990).

Para alcançar segurança microbiológica, a quantidade de calor necessária para inativar a Coxiella burnetii é a base para o processo de pasteurização correntemente aplicado ao leite, sendo a monitoração da adequabilidade da pasteurização Grade A do leite feita pelo teste de fosfatase. Também, bactérias aeróbias e coliformes do leite pasteurizado são comumente enumeradas (KNUTSON et al, 1988).

Para MUDGET e SCHWARTZBERG (1982), desde que Fleming descobriu durante a Segunda Guerra Mundial que altas frequências eletromagnéticas apresentavam um efeito letal sobre a bactéria E.coli, vem havendo interesse crescente no uso das microondas para a pasteurização e 
esterilização de alimentos. Mais ou menos na mesma época, de acordo com dados da agenda industrial, o Dr. Percy Spencer da Raytheon Company (EUA), noticiou uma sensação de formigamento nas mãos em proximidades à um magnetron teste e rapidamente percebeu que as microondas poderiam ser utilizadas para aquecer alimentos. Isto levou ao desenvolvimento do primeiro forno de microondas, o qual ele chamou de "Radarange".

A técnica básica do aquecimento pelas microondas é conhecida há mais de 40 anos. Durante os últimos 20 ou 30 anos, muitos estudos originaram-se com relação ao seu potencial para o processamento de alimentos. As operações nas quais as microondas tem sido aplicadas, pelo menos experimentalmente, incluem pasteurização, esterilização, branqueamento, têmpera, degelo e controle de pragas (YOUNG e JOLLY, 1990).

É cada vez mais importante a nível industrial e doméstico a utilização do forno de microondas, um sistema de geração de calor dentro do alimento por energia eletromagnética. $\mathrm{O}$ aumento da temperatura se dá devido ao fato das moléculas dos alimentos estarem em movimento contínuo como consequência de uma distribuição irregular de suas cargas, e estes movimentos originam friç̧ões intermoleculares que por sua vez geram calor no interior da substância (TEJERA e HARDISSON de la TORRE, 1991). Nenhum meio de transferência de calor está envolvido e, há uma pequena dependência na condução do calor dentro do próprio alimento, de tal modo que a temperatura do alimento é elevada muito rapidamente (SALE, 1976; TEJERA e HARDISSON de la TORRE, 1991).

As microondas não penetram no metal, assim os alimentos não podem ser aquecidos em latas. Em contrapartidas, as microondas atravessam plásticos, papel e vidros e desta forma alimentos contidos nestes materiais poderão ser aquecidos (SALE, 1976). Para CALVO e OLANO (1992). a 
esterilização do leite de vaca em sacos plásticos em porções individuais deverá ter um futuro atrativo e poderá ser de extensivo uso comercial nos próximos anos.

$\mathrm{O}$ uso das microondas oferece inúmeras vantagens sobre os métodos convencionais de processamento térmico. $\mathrm{O}$ aquecimento por microondas pode ser mais rápido e uma distribuição mais uniforme do calor através do produto pode ser alcançada de melhor forma do que nos procedimentos convencionais (CALVO e OLANO, 1992). A capacidade em diminuir o tempo de aquecimento dos alimentos depende da potência do forno microondas e da umidade do alimento. A eficácia da penetração pelas microondas se determina através da profundidade pela qual a metade da energia eletromagnética que incide sobre a superficie do produto, se transforma em calor. Esta penetração está em relação inversa com a freqüência, de modo que em produtos de maior espessura convém utilizar ondas de baixa freqüência. Considera-se microondas as radiações eletromagnéticas cuja freqüência se encontra no intervalo compreendido entre 3 e $300.000 \mathrm{Mhz}$, sendo que as mais utilizadas são as de 915 e $2450 \mathrm{MHz}$ (TEJERA e HARDISSON de la TORRE, 1991). Vários estudos sobre o tratamento térmico do leite tem sido dirigido com relação a efetividade deste por diferentes caminhos, sendo o controle da redução do número de bactérias aeróbias o mais comum (KNUTSON et al, 1988).

A aplicação do aquecimento pelas microondas para produtos alimentícios, na maior parte das vezes, envolve equipamentos domésticos (JAYNES, 1975). A aplicação das microondas na indústria láctea inclue eficiente pasteurização, termalização do leite antes da produção do queijo, inativação de bacteriófagos e redução das bactérias termodúricas e psicrotróficas do leite com o objetivo de extender seu tempo de armazenamento (VASAVADA, 1990). 


\subsection{O microondas e a qualidade química do leite de vaca}

O calor induz mudanças de elevado significado tecnológico na desnaturação das proteínas do soro do leite, levando à formação de complexos proteína/caseína, os quais afetam a coagulação do leite e a produção do queijo (CALVO e OLANO 1992).

A relação proteína/caseína do soro é ligeiramente maior no leite tratado por microondas, segundo estudos de MERIN e ROSENTHAL ${ }^{1}$ (1984), citado por CALVO e OLANO (1992), que compararam o efeito das microondas (700W e $2450 \mathrm{Mhz})$ aos tratamentos convencionais, o que sugere uma maior desnaturação das proteínas do soro. Os estudos também relataram que, o aquecimento por microondas, além de ser mais rápido que os convencionais e ainda reduzir efetivamente o número de microrganismos patogênicos, desativa a enzima fosfatase alcalina.

Alguns estudos relatam isomerização de aminoácidos em alimentos protéicos tratados termicamente por microondas, o que diminuiria o seu aproveitamento protéico (LUBEC et al $^{2}, 1989$, citado por CALVO e OLANO, 1992: CHEN et al ${ }^{3}, 1989$, citado por FAY, 1991). Entretanto, FAY et al (1991), após aquecerem em forno microondas, leite tratado anteriormente pelo método UHT e 3 diferentes fórmulas infantis, não observaram nenhuma mudança significativa nas amostras tratadas em microondas quando comparadas com as não

\footnotetext{
${ }^{1}$ MERIN. R. : ROSENTHAL. I. Pasteurization of milk by microwave radiation. Milchwissenschalf. Nurnberg. 39(11): $643+1984$. apud CALVO. M. M.: OLANO. A. Thermal treatments of goat's milk. Ciência y Tecnologia de Alimentos. Valência. 32(2): 139-52. 1992.

'LUBEC. G. et al. Amino acid isomerization and microwave exposure. Lancet. London. 334: 1392. 1989. apud CALVO. M. M.: OLANO. A. Thermal treatments of goat's milk. Ciência : Tecnologia de Alimentos. Valência. 32(2): 139-52. 1992.

${ }^{3}$ CHEN. S. T.: WU. S. H.: WANG. K. T. Rapid isomerization of optically active amino acids by microwave oven-based heating treatment. International Journal of Peptide and Protein Research. Copenhagen. 33: 73-5. 1989. apud FAY. L.: RICHLI. U. I.: LIARDON. R. Eridence for the absence of amino acid isomeration in microwave- heated milk and infant formulas. Journal of Agricultural and Food Chemistry. Washington. 39(10): 1857-9. 1992.
} 
tratadas. Os autores relatam que estes resultados, mediante utilização das microondas em condições correspondentes àquelas normalmente aplicadas ao aquecimento de alimentos, não foram praticadas nos outros estudos que utilizaram temperatura, $\mathrm{pH}$ e tempo não convencionais às práticas tradicionais, justificando assim os resultados contraditórios.

\subsection{O microondas e a qualidade microbiológica do leite de vaca}

Os tratamentos térmicos aplicados ao leite tem um efeito bactericida. o qual é o objetivo do processo, e assim, trazem benefícios.

O elevado número de coliformes presentes em algumas amostras de leite sugere que estes foram produzidos sob condições higiênicas extremamente carentes (CALVO e OLANO, 1992). As bactérias psicrotróficas, são as de maior importância na tecnologia moderna de alimentos já que crescem nos limites de tempo em que os alimentos estão armazenados em temperatura de refrigeração. Os vários métodos capazes de extender com sucesso a vida útil dos alimentos a uma dada temperatura, atrasam ou inibem o crescimento de Pseudomonas, sendo a maioria das psicrotróficas facilmente destruídas por um aquecimento relativamente moderado (CUNNINGHAM, 1980).

As bactérias psicrotróficas são capazes de produzir lipases e proteases extracelulares, e a inativação destas enzimas tem sido objeto de numerosas investigações, porque algumas destas não são inativadas durante a pasteurização ou tratamento UHT e elas podem produzir mudanças bioquímicas durante o armazenamento do leite (CALVO e OLANO, 1992).

Os efeitos das microondas sobre os microrganismos em alimentos são influenciados pelas características intrínsecas dos alimentos $(\mathrm{pH}$, umidade, potencial de óxido-redução, constituintes antimicrobianos, estruturas biológicas, composição química, tamanho ou forma do alimento) e fatores extrínsicos 
(temperatura, umidade e gases do ambiente, freqüência $\mathrm{e}$ intensidade da irradiação, tempo de exposição às microondas, posição do alimento no campo efetivo da irradiação, entre outros). Além do mais, a composição química e física dos microrganismos que estão sendo irradiados, seu estágio de crescimento (célula vegetativa, esporo ou fase de crescimento, úmido ou seco, etc.) e número inicial, também são fatores importantes. As espécies de bactérias diferem quanto à susceptibilidade à inativação por microondas (FUNG e CUNNINGHAM, 1980).

CUNNINGHAM (1980) investigou as possibilidades de utilizar o tratamento por microondas para reduzir ou eliminar psicrotróficas que causam deterioração em carne fresca à temperatura de refrigeração. $O$ autor submeteu culturas puras de bactérias em caldo nutriente $\left(10^{7}-10^{8} \mathrm{cels} / \mathrm{ml}\right)$ e produtos cárneos crus (carne, frango e pele de frango) à exposição às microondas à 915 ou $2450 \mathrm{Mhz}$. As culturas utilizadas para o teste foram: Pseudomonas fluorescens, P.aeroginosa, P.toetrolens, P.synthaxa, P.syncyanea, Flavobacterium devorans, F.auratiacum, F.aquatile, Alcaligenes faecalis, A.viscolactis, Achromobacter, A.parvulus e A.pestifer.

Após vários tempos de exposição, as temperaturas foram anotadas e as amostras seguiram para contagem em placas para determinação dos sobreviventes. Em caldo nutriente todas as contagens de psicrotróficas foram dramaticamente reduzidas em exposição curta ( 5 a 20 segundos) à irradiação microondas. Em alguns casos, contagens iniciais de $10^{7}-10^{8} \mathrm{cels} / \mathrm{ml}$ foram reduzidas a zero após 15 segundos de exposição e a temperatura anotada neste tempo foi $60^{\circ} \mathrm{C}$. Pseudomonas aeroginosa foi a psicrotrófica mais resistente testada, enquanto Pseudomonas synthaxia e Alcaligenes viscolactis foram extremamente sensíveis à irradiação das microondas.

Quanto aos pedaços de frango expostos às microondas, a contagem total e o número de coliformes diminuíram com o aumento do tempo de tratamento. Após 40 segundos, todas as contagens foram marcadamente 
reduzidas, em alguns casos, em aproximadamente 2 ciclos de log. Coliformes iniciais (NMH) apresentavam média 100, que foi reduzida à 50, em 20 segundos de exposição às microondas. Redução acentuada também foi notada nas peles de frango expostas às microondas.

Os resultados indicaram que as bactérias responsáveis pela deterioração de alimentos refrigerados são altamente sensíveis ao tratamento por microondas, resultando em um aumento do tempo de vida útil do mesmo, o que pode ser empregado para o uso comercial e doméstico.

CHOI et al (1992), submeteram à ação de microondas amostras de leite integral esterilizado inoculados com $10^{6}-10^{7} \mathrm{cels} / \mathrm{ml}$ de L.monocytogenes, Y.enterocolítica ou C.jejuni à uma temperatura de $71,1^{\circ} \mathrm{C}$ por mais de 60 minutos em um forno de microondas caseiro (2450 Mhz; $1680 \mathrm{~W}$ ), com o objetivo de se avaliar a inativação destes microrganismos patogênicos. Após o tratamento térmico, as amostras foram armazenadas à $4^{\circ} \mathrm{C}$ por 15 a 20 dias e a população microbiana sobrevivente foi determinada por plaqueamento direto em meio apropriado. A presença de microrganismos injuriados ou estressados foi determinada semanalmente por plaqueamento em meio sólido após crescimento em caldo enriquecido, em intervalos de 2 meses. Os resultados mostraram que o aquecimento a $71,1^{\circ} \mathrm{C}$ em microondas por 2,8 e 10 minutos inativa todas as células de C.jejuni, $Y$ enterocolítica e L.monocytogenes, respectivamente. Entretanto, tratamentos térmicos mais curtos resultam em sobrevivência ou injúria subletal dos microrganismos, o que pode ser evidenciado após crescimento em caldo enriquecido. A inativação térmica da L.monocytogenes por microondas foi influenciada pelo tamanho da amostra e método de aquecimento.

Outras pesquisas de CHOI et al (1993) demostraram que amostras de leite inoculado com $10^{6}-10^{7} \mathrm{cels} / \mathrm{ml}$ de Y.enterocolítica e C.jejuni expostas em banho maria às microondas por 8 e 3 minutos respectivamente, inativa todas as células microbianas. Os mesmos autores realizaram experimentos similares 
com amostras de leite inoculadas com L.monocytogenes e encontraram que a exposição às microondas das amostras em banho maria por 10 minutos inativa todas as células do microrganismo.

Existem trabalhos conflitantes na literatura com relação aos efeitos letais das microondas sobre os microrganismos (CUNNINGHAM, 1980; AKTAS e OZILGEN, 1992).

Segundo trabalhos de FLEMING ${ }^{4}$ (1944), citado por MUDGETT e SCHWARTZBERG (1982) a energia das elevadas frequências foram estudadas extensivamente por muitos pesquisadores para determinar se os efeitos eram de origem térmica ou atérmica. Enquanto Fleming acreditava que a destruição microbiana era devido a algum efeito atérmico misterioso, tem sido demonstrado que o efeito letal da energia das microondas é apenas de origem térmica. A letalidade microbiana é agora conhecida como resultado da penetração em um material biológicamente úmido pelas ondas eletromagnéticas, as quais aquecem fluídos intra e extracelulares por transferência de energia das moléculas dipolares da água e ions dissolvidos. Isto resulta em geração de calor dentro do material devido a fricção molecular.

Já outros pesquisadores acreditam que, efeitos eletromagnéticos não térmicos das microondas "per se" são responsáveis pela inativação microbiana. YOUNG e JOLLY (1990) afirmam que as microondas certamente podem ter efeito atérmico sobre as reações químicas. Entretanto, há ainda muito pouco conhecimento sobre a variação do mecanismo de morte microbiana pelas microondas, realizadas no mesmo equipamento sob condições experimentais semelhantes (FUNG e CUNNINGHAM, 1980; AKTAS e OZILGEN, 1992).

${ }^{4}$ FLEMING. H. Electrical Engeniring. Chippemdale. 63: 18. 1944. apud MUDGETT. R. E.: SCHWARTZBERG. H. G. Microwave food processing: pasteurization and sterilization. AIChE-Symposium Series. New York. 78(218): 1-11. 1982. 
As principais razões que permitem a sobrevivência de microrganismos em alimentos após o processamento por microondas podem ser um aquecimento irregular e estrutura do alimento, se é grande ou de forma heterogênea. $O$ forno microondas pode aquecer os alimentos em tempo muito curto, o qual pode ser suficiente para destruir todos os microrganismos. Já o processamento inadequado com microondas pode apenas injuriar, mas não matar os microrganismos.

Os microrganismos podem ser injuriados por tratamento subletal com calor, congelamento, radiação ionizante ou não ionizante, microondas, etc. As células injuriadas são potencialmente mais nocivas do que as células não injuriadas, porque elas podem escapar da detecção, já que não se desenvolverão em meio seletivo enquanto estão inativas, reparando-se e produzindo toxinas.

Segundo AKTAS e OZILGEN (1992), há poucos estudos disponíveis na literatura com relação à injúria microbiana pelas microondas. Estes avaliaram a injúria e a morte de E.coli por microondas em um reator tubular contínuo de pasteurização e encontraram que geralmente 15 a 25\% dos microrganismos sobreviventes foram injuriados. Esta porcentagem aumentou drasticamente em condições próximas à de esterilização total. Estes microrganismos injuriados podem ser potencialmente perigosos em processos de esterilização por microondas.

\subsection{Tratamento do leite utilizando microondas}

Materiais homogêneos podem ser pasteurizados ou esterilizados por microondas, sem superaquecimento das bordas superficiais ou subaquecimento do centro, em contraste aos métodos de aquecimento convencionais com lenta penetração do calor. Assim, elevadas temperaturas superficiais não são empregadas em aquecimento por microondas e a temperatura do centro necessária 
para a destruição dos microrganismos é mais rapidamente alcançada. Isto leva ao desenvolvimento de processos com utilização de microondas para alimentos com maior retenção de nutrientes termo-lábeis, vitaminas e constituintes de flavour e com tempos de processamento tão pequenos quanto $5-10 \%$ daqueles obtidos no aquecimento convencional. Os fluidos aquosos podem ser processados em banho ou em tratamento continuo (MUDGETT e SCHWARTZBERG, 1992). Para FUNG e CUNNINGHAM (1980), um dos principais aspectos envolvidos no uso das microondas tem sido a idéia de pasteurizar ou esterilizar alimentos a mais baixas temperaturas e menores tempos do que aqueles necessários aos métodos convencionais.

MUDGETT ${ }^{5}(1980)$, citado por YOUNG e JOLLY (1990) pasteurizou o leite utilizando microondas e relatou que a qualidade do leite foi melhor do que a do leite convencionalmente tratado, devido ao aquecimento rápido e uniforme. YOUNG e JOLLY (1990) afirmam que devido à ausência de superficies quentes em contato direto com o leite, há redução da desnaturação térmica.

HAMID et al $^{6}$ (1969), citado por KNUTSON (1987) utilizaram os métodos contínuos e descontínuos para pasteurizar leite integral crú em equipamento de $1200 \mathrm{~W}$ à $2450 \mathrm{Mhz}$. No método de descontínuo (banho), $16 \mathrm{ml}$ da amostra foi tratada em microondas por 10,12 e 14 segundos, alcançando temperaturas de $74,4,79,4$ e $88,9^{\circ} \mathrm{C}$, respectivamente. A 10 e 12 segundos, ocorreu $99,99 \%$ de redução da contagem bacteriana total a partir de uma contagem inicial de $2 \times 10^{8} \mathrm{cels} / \mathrm{ml}$, enquanto que a 14 segundos não foi detectada sobrevivência microbiana. O método contínuo foi menos eficiente $(92,7 \%)$ na

\footnotetext{
MUDGETT. R.E. Journal of Food Process Engeneering. Westport. 3:217. 1980. apud YOUNG. G. S.: JOLLY. P. G. Microwaves: the potencial for use in dain: The Australian Journal of Dairy Technology. Melbourne. 45(5): 34-7. 1990.

"HAMID. M. A. K. et al. Microwave pasteurization of raw milk. Journal of Microwave Power. Ottawa. 4: 272-5. 1969. apud KNUTSON. K. M. et al. Microwave heating of food. Lebensmittel Wissenschaft und Technologie. London. 20(3): 101-10. 1987.
} 
redução da contagem bacteriana total, sendo que 7 amostras foram avaliadas. Os últimos resultados foram atribuídos à variações na temperatura do processamento, que foi dado como média $82,2^{\circ} \mathrm{C}$.

Em outro estudo, JAYNES (1975) utilizou o método contínuo de pasteurização por microondas, no qual o leite de vaca crú foi bombeado através de um equipamento, onde foi aquecido pelas microondas à $2450 \mathrm{Mhz}$ e resfriado, para assemelhar-se com o processo HTST de pasteurização. As temperaturas foram medidas na entrada e na saída do equipamento. Os tempos alcançados nos 3 fluxos analisados foram 1,14 segundos para $200 \mathrm{ml} /$ minuto, 0,76 segundos para $300 \mathrm{ml} /$ minuto e 0,57 segundos para $400 \mathrm{ml} /$ minuto. A eficiência da pasteurização foi avaliada pelo teste de fosfatase, plaqueamento padrão e contagem de coliformes. A avaliação sensorial foi feita. O leite controle foi pasteurizado em banho maria à temperatura constante de $62,8^{\circ} \mathrm{C}$ por 30 minutos. Os resultados para o leite tratado com microondas e as amostras controle mostraram que todos os testes fosfatase foram negativos, contagem de coliformes de todas as amostras $<1 /$ ml e a contagem padrão em placas foi similar entre os tratamentos. Dos 27 analistas que avaliaram sensorialmente os leites tratados com microondas e o controle, 10 notaram diferença, dos quais 8 preferiram o leite tratado por microondas.

EL-SHIBINY et al ${ }^{7}(1982)$, citado por KNUTSON et al (1987), submeteram o leite de búfala cru ( $50 \mathrm{ml} /$ amostra) ao tratamento por microondas ( $2400 \mathrm{~W}$ ) por $120,130,140$ e 150 segundos, alcançando as temperaturas de 86 , 94,96 e $98^{\circ} \mathrm{C}$, respetivamente. Análise foram feitas com relação à distribuição de nitrogênio (caseína, proteína do soro e conteúdo nitrogenado não protéico), acidez, $\mathrm{pH}$, coagulação por renina e estabilidade ao etanol. Os resultados quanto à aceitabilidade foram observados em todas as análises. O conteúdo de nitrogênio

\footnotetext{
EL-SHIBINY. S. et al. Effect of microwaves on buffalo's milk. Egyptian Journal of Dairy Science. Cairo. 10: 29-34. 1982. apud KNUTSON. K. M. et al. Microwave heating of food. Lebensmittel Wissenschaft und Technologie. London. 20(3): 101-10. 1987.
} 
não protéico não foi afetado, sugerindo que as cadeias protéicas do leite nâo foram quebradas durante o tratamento. A contagem bacteriana total diminuiu acima de 99,5\%, avaliada um dia após o tratamento, e ocorreram menores contagens correspondentes às amostras tratadas por mais tempo. Coliformes não foram detectadas durante 4 dias de armazenamento a temperatura ambiente $\left(25^{\circ} \pm 5^{\circ} \mathrm{C}\right)$

Para simular a pasteurização doméstica por microondas, MERIN e ROSENTHAL $^{8}$ (1984), citado por KNUTSON et al (1987), compararam o leite crú $(400 \mathrm{ml})$ tratado por 30 minutos em forno microondas (2450 Mhz, $700 \mathrm{~W}$ ) com leite cru tratado por 30 minutos em banho maria à $63^{\circ} \mathrm{C}$. Os resultados foram similares entre os tratamentos: a contagem padrão em placa diminuiu, os psicrotróficos diminuíram, os coliformes não foram detectados, o teste de fosfatase foi negativo e a composição química dos leites estava similar. Após 3 minutos de aquecimento por microondas, uma drástica redução na contagem padrão em placas foi observada e o teste de fosfatase foi negativa.

Devido ao objetivo da pasteurização do leite ser eliminar todos os patógenos na forma vegetativa, a avaliação da redução da contagem total não é suficiente. DEIBEL et al ${ }^{9}$ (sdp), citado por KNUTSON et al (1987), foram os primeiros a compreender a importância de um microrganismo específico, Campylobacter jejuni, em leite tratado por microondas. Eles constataram que após 3 minutos de aquecimento por microondas de $200 \mathrm{ml}$ de leite cru inoculado, houve redução da concentração de C.jejuni L-7 por 4 ordens de magnitude, a

\footnotetext{
${ }^{8}$ MERIN. R. : ROSENTHAL. I. Pasteurization of milk by microwave radiation. Milchwissenschalf. Nurnberg. 39(11): 6434 . 1984. apud KNUTSON. K. M. et al. Microwave heating of food Lebensmittel Wissenschaft und Technologie. London. 20(3): 101-10. 1987.

${ }^{y}$ DEIBEL. K. E. et al. Destruction of Campylobacter jejuni by microwave heating. Unpublished data. Department of Food Science and Nutrition. The Ohio State University. Colombus. OH. apud KNUTSON. K. M. et al. Microwave heating of food. Lebensmittel Wissenschaft und Technologie. London. 20(3): 101-10. 1987.
} 
partir da contagem inicial de $10^{5}-10^{6} \mathrm{cels} / \mathrm{ml}$, mesmo com temperatura final de 70 $80^{\circ} \mathrm{C}$.

Um estudo de CHIU et al ${ }^{10}(1984)$, citado por KNUTSONet al (1987), objetivou melhorar a vida útil do leite pasteurizado. $O$ aquecimento por microondas do leite de vaca de 8 dias a $60^{\circ} \mathrm{C}(200 \mathrm{ml}$ por 120 segundos) reduz a contagem bacteriana de psicrotróficos a um nível indetectável a partir de uma contagem inicial de $1,8 \times 10^{6} \mathrm{cels} / \mathrm{ml}$, extendendo então a vida útil do leite.

JAYNES (1974) efetuou a pasteurização do leite em processo de microondas contínuo, à $72^{\circ} \mathrm{C}$ por 15 segundos. A adequação do tratamento foi avaliada por teste de fosfatase negativo e redução da contagem bacteriana em placa, comparado com tratamento controle a $62,8^{\circ} \mathrm{C}$ por 30 minutos. O teste triangular não mostrou nenhuma diferença significativa no flavour entre o leite pasteurizado com microondas e o controle.

KNUTSON et al (1988), com o objetivo de desenvolverem um método caseiro para pasteurização do leite, submeteram leites inoculados e não inoculados ao tratamento em forno de microondas. A seleção dos microrganismos para o estudo foi baseada em sua importância no leite e a resistência relativa ao calor da Coxiella burnettii. Foram utilizados Salmonella typhimurium, E.coli, Pseudomonas fluorescens e Streptococcus faecalis.

Os processos de pasteurização foram simulados utilizando-se leite tratado em forno microondas. Quando repetido com leite inoculado, um número excessivo de microrganismos testes algumas vezes persistiam ao tratamento térmico, provavelmente devido à distribuição desuniforme do calor através do leite, o que demonstra a necessidade da homogeinização dos alimentos fluídos enquanto tratados para que se alcance temperaturas uniformes, não favorecendo a

\footnotetext{
${ }^{16}$ CHIU. C. P. et al. Microwave treatment of pasteurized milk. Journal of Microwave Power. Ottawa. 19: 269-72. 1984. apud KNUTSON. K. M. et al. Microwave heating of food. Lebensmittel Wissenschaft und Technologie. London. 20(3): 101-10. 1987.
} 
injúria microbiana, principal falha, segundo HEDDLESON, DOORE e ANANTHESWARAN (1994), para o insucesso do tratamento do leite.

STEARNS e VASAVADA (1986) utilizaram um forno de microondas caseiro para pasteurizar $15 \mathrm{ml}$ de leite cru, a uma potência de 2450 Mhz por períodos entre 0 e 90 segundos. Aplicaram-se os testes de contagem padrão e coliformes para determinação da segurança microbiológica do leite e avaliação organoléptica para determinação da vida útil da amostra tratada termicamente. Tanto a contagem padrão quanto o número de coliformes diminuíram e o tratamento aumentou o tempo de vida útil do leite. A exposição durante 65 segundos resultou em quase completa inativação dos microorganismos (>99,9\%). O leite cru apresentou-se organolepticamente insatisfatório após 1 semana de armazenamento a $4{ }^{\circ} \mathrm{C}$ enquanto que, o leite tratado por microondas por tempo igual ou superior à 35 segundos, apresentou-se com qualidade aceitável após 2 semanas de armazenamento a $4^{\circ} \mathrm{C}$.

THOMPSON e THOMPSON (1990) demonstraram a eficácia do tratamento do leite de cabra em microondas caseiro com redução da contagem total abaixo de $6 \log$ (média $5 \mathrm{log}$ ), sem alteração da qualidade organoléptica do leite. A temperatura alcançada (potência média) foi de $65^{\circ} \mathrm{C}$ por 30 minutos nas 25 amostras analizadas. Em estudos prévios dos autores, a temperatura de $75^{\circ} \mathrm{C}$ promoveu flavour de "cozido" ao leite de cabra. A eficácia da pasteurização do leite de cabra por microondas caseiro sugere sua aplicação para pasteurização do leite de vaca segundo os autores, seguindo a mesma metodologia.

SIMS et al (1991) trataram termicamente leite de vaca obtido de um laticínio, às temperaturas de $72,8^{\circ} \mathrm{C}$ por 0,15 e 30 segundos em um processo continuo de microondas em $700 \mathrm{~W}$ e $2450 \mathrm{Mhz}$. O leite pasteurizado foi analisado pelos métodos de contagem padrão em placas e contagem de bactérias psicrotróficas pelos métodos convencionais e impedimétrico após $0,7,14$ e 21 dias de armazenamento à $4{ }^{\circ} \mathrm{C}$. Foi conduzida também a avaliação da 
aceitabilidade organoléptica do leite. Os resultados indicaram que enquanto o processamento do leite por microondas resultou em redução inicial da contagem microbiana, ambos testes de plaqueamento tiveram contagens aumentadas durante o armazenamento à $4^{\circ} \mathrm{C}$. Em 21 dias, $93 \%$ das amostras mostraram contagem de psicrotróficas entre $10^{5}-10^{6} / \mathrm{ml}$. O tempo de detecção de impedância (TDI) das amostras de leite aumentaram. A pasteurização por microondas não produziu valores substancialmente menores quanto à contagem total e contagem de psicrotróficos do que os obtidos pelos métodos convencionais de pasteurização. Tipicamente, as amostras de leite demonstraram elevados valores de TDI, apresentaram uma menor contagem total e niveis indetectáveis de psicrotróficos. Entretanto, uma pequena porcentagem de amostras mostrou o TDI de deterioração anterior aos 21 dias. Baseado no TDI do leite pré-incubado à $18^{\circ} \mathrm{C}$ por 24 horas, o potencial de vida de prateleira do leite pasteurizado por processo contínuo de microondas estava entre 7 e 14 dias. Os dados demonstraram que o tratamento térmico por microondas à $72{ }^{\circ} \mathrm{C}$ ou $80^{\circ} \mathrm{C}$ por 15 ou 30 segundos foi viável para a pasteurização do leite.

KUDRA et al (1991) utilizaram um forno de microondas caseiro ( $700 \mathrm{~W}$ e $2450 \mathrm{Mhz}$ ), adaptado para pasteurização contínua de leite de vaca e creme, às potências de 100 e $80 \%$. Maior eficácia e uniformidade da temperatura nas amostras foi alcançada à potência $100 \%$ e à menor potência, oscilações importantes de temperatura ocorreram. Conclui-se que o sistema contínuo de aquecimento por microondas pode ser utilizado para pasteurização de ambos os produtos testados. VILLAMIEL et al (1996), em estudos similares garantem que o processamento contínuo por microondas é eficaz e assemelha-se à pasteurização tratando-se do leite de vaca.

Segundo KNUTSON et al (1988) o aquecimento por microondas causa uma distribuição desuniforme de calor no alimento, o qual deve ser manualmente misturado (por agitação ou batimento) durante o tratamento por 
microondas para obter uma temperatura uniforme e então uma exposição adequada dos microrganismos ao calor através do alimento.

A habilidade das microondas em penetrar rapidamente materiais de embalagem não metálicos leva este método a ser utilizado no tratamento térmico de produtos alimentares após o empacotamento (YOUNG e JOLLY, 1990). O principal problema encontrado para o tratamento térmico do leite utilizando é a dificuldade em adaptar embalagens plásticas ao calor a que serão expostas sem alterações tanto da qualidade da embalagens quanto do produto final (SALE, 1976). 


\section{MATERIAL E MÉTODOS}

\subsection{Material}

\subsubsection{Leite}

Foi utilizado leite de vaca integral, da ordenha do dia (período da manhã), do rebanho do Departamento de Zootecnia da Escola Superior de Agricultura Luiz de Queiroz (ESALQ), acondicionado em embalagens plásticas de um litro e mantido sob refrigeração $\left(<10^{\circ} \mathrm{C}\right)$ até o momento do tratamento, no mesmo dia e período.

\subsubsection{Forno microondas}

O aparelho utilizado foi o Forno de Microondas modelo Wave 400

da marca Consul, com prato giratório e potência máxima de saída de $700 \mathrm{~W}$ e frequência de microondas de $2450 \mathrm{Mhz}$. 


\subsection{Métodos}

\subsubsection{Amostragem do leite cru}

Após homogeinização, amostras do leite cru foram retiradas para análises microbiológicas, contagem total e coliformes, e também fisico-químicas, pH e acidez titulável.

\subsubsection{Tratamento do leite em forno de microondas caseiro}

Em um becker com capacidade de $3000 \mathrm{ml}, 1000 \mathrm{ml}$ de leite integral in natura pré resfriado foram transferidos para o forno microondas e submetidos à ação das microondas por 5,10 e 15 minutos à potência máxima (100\%). A cada 2,5 minutos procedia-se a homogeinização da amostra com um bastão de vidro. Após cada tempo estipulado de tratamento, amostras de aproximadamente $40 \mathrm{ml}$ foram retiradas e colocadas em banho de gelo até o momento de análise. Durante um dos tratamentos, a temperatura foi aferida aleatoriamente, a cada homogeinização. 


\subsection{Análises}

Ao leite cru e às amostras resfriadas do leite submetido às microondas, foram realizadas análises físico-químicas e microbiológicas, visando o grau de segurança conforme a SAA-Resolução $n^{0} 24$ da Secretaria de Agricultura e Abastecimento do Estado de São Paulo, de 01/08/94.

\subsubsection{Análises físico químicas}

- pH: através do uso de potenciômetro Digimed DMPH-2.

- acidez: pelo método descrito nas Normas Analíticas do Instituto Adolfo Lutz, que determina volumetricamente a acidez do leite pelo uso de solução de hidróxido de sódio $0,1 \mathrm{~N}$ na presença do indicador fenolftaleína a $1,0 \%$.

\subsubsection{Análises microbiológicas}

- Coliformes totais: determinado por cultivo em meio seletivo conforme o STANDARD Methods for the Examination of Dairy Products (1985). A composição do meio utilizado encontra-se na Tabela 1 do Apêndice

- Contagem de bactérias totais: através de cultivo em Agar Padrão (PCA) conforme o STANDARD Methods for the Examination of Dairy Products (1985). A composição do meio utilizado encontra-se na Tabela 2 do Apêndice. 


\subsection{Análise estatística}

$\mathrm{Na}$ análise estatística foi empregado o Delineamento em Blocos ao Acaso, com 10 Blocos (repetições) e 3 Tratamentos (potência de $100 \%$ e 3 diferentes tempos: 5, 10 e 15 minutos). Foram aplicados os testes de Tukey e Dunnet.

À seguir encontra-se o esquema da análise da variância.

\begin{tabular}{lc} 
C.V. & G.L. \\
\hline Blocos & 9 \\
Tratamentos & 2 \\
Residuo & 18 \\
\hline Total & 29
\end{tabular}


LEITE CRU RESFRIADO (1Lt) BÉCKER $3000 \mathrm{ml}$

$\Downarrow$

AMOSTRA DE $\pm 40 \mathrm{ml}$ EM BANHO DE GELO

$\Downarrow$

FORNO DE MICROONDAS (Pot 100\%)

$\downarrow$

5 MINUTOS DE EXPOSIÇÃO

Homogeneização aos 2,5 minutos

U

AMOSTRA DE \pm 40ml EM BANHO DE GELO

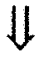

10 MINUTOS DE EXPOSIÇÃO

Homogeneizaçāo aos 7,5 minutos

U

AMOSTRA DE $\pm 40 \mathrm{ml}$ EM BANHO DE GELO

U

15 MINUTOS DE EXPOSIÇĀO

Homogeneizaçāo aos 12,5 minutos

$\Downarrow$

AMOSTRA DE $\pm 40 \mathrm{ml}$ EM BANHO DE GELO

$\Downarrow$

ANÁLISES MICROBIOLÓGICAS COLIFORMES TOTAIS

- Cultivo em meio seletivo VRBA

- Plaqueamento em profundidade

- Incubação por $48 \mathrm{hs}$ à $35 \pm 1.0^{\circ} \mathrm{C}$

- Colónias puntiformes vermelho brilhante

BACTÉRIAS TOTAIS

- Cultivo em PCA

- Plaqueamento em superficie

- Incubação por $48 h s$ à $35 \pm 1.0^{\circ} \mathrm{C}$

ANÁLISES FÍSICO QUIMMICAS pH

- Potenciômetro Digimed DMpH-2 ACIDEZ TITULÁVEL

- Determinação volumétrica pelo uso de solução de hidróxido de sódio $0.1 \mathrm{~N}$ na presença do indicador fenolftaleina a $1.0 \%$ segundo descrito nas NORMAS Analiticas do Instituto Adolfo Lutz (1985)

- Colônias

"STANDARD Methods for the

Examination of Dairy Products"

(1985)

$\Downarrow$

ANÁLISE ESTATÍSTICA 


\section{RESULTADOS E DISCUSSÃO}

Os resultados obtidos para $\mathrm{pH}$, acidez, contagem de bactérias totais e coliformes totais do leite de vaca antes e após ser submetido à ação de microondas, encontram-se, respectivamente, nas Figuras 1, 2, 3 e 4, e nas Tabelas $3,4,5$ e 6 contidas no Apêndice.

Há dificuldades para comparação dos resultados deste com outros estudos, uma vez que diferentes tipos de forno microondas, condições (tempo e temperatura) de aquecimento, volume de leite tratado e processos utilizados (contínuos e descontínuos) são preconizados.

Mesmo não sendo a temperatura parâmetro de discussão no presente trabalho, a Tabela 7, contida no Apêndice demonstra as temperaturas alcançadas nos diferentes tempos de exposição. Vale lembrar que, as temperaturas feridas constam de apenas um tratamento aleatório.

\subsection{Efeito do tratamento sobre o pH}

Os dados de variação do $\mathrm{pH}$ do leite após submetido à ação de microondas são encontrados na Figura 1.

De acordo com o teste bilateral de Dunnet, a variação do $\mathrm{pH}$ foi significativa $(p \leq 0,01)$ para os tratamentos de 10 e 15 minutos, que não diferem entre si (Teste de Tukey). 
Embora tenha ocorrido variação do $\mathrm{pH}$ do leite para os tratamentos de 10 e 15 minutos, estas não prejudicam as características físico químicas do leite, uma vez que o $\mathrm{pH}$ médio após estes tratamento foi apenas ligeiramente inferior àquele do leite sem nenhum tratamento, ou seja, $\mathrm{pH}=6.7$ para o leite cru e 6.65 e 6.63 para os tempos de tratamento de 10 e 15 minutos, respectivamente.

Dos trabalhos revisados, nenhum estudo semelhante à este relata alteração importante do $\mathrm{pH}$ do leite de vaca tratado por microondas.

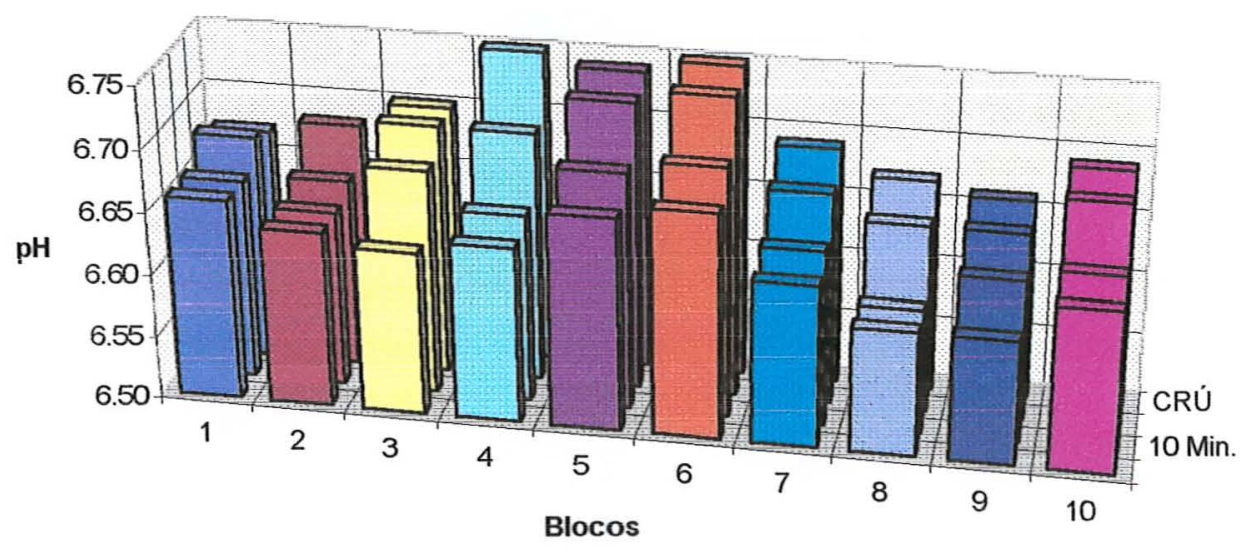

Figura 1. Ação das microondas sobre o pH do leite de vaca

\subsection{Efeito do tratamento sobre a acidez titulável}

As variações da acidez titulável do leite pelo tratamento com microondas são apresentadas na Figura 2 e na Tabela 4 do Apêndice.

A análise estatística dos dados (Teste de Dunnet), mostrou que a variação da acidez titulável pelo tratamento com microondas não foi significativa. 
Assim sendo, pode-se afirmar que o uso de microondas não afeta as características físico químicas e organoléticas do leite, uma vez que a acidez titulável permaneceu dentro dos limites estabelecidos pela Resolução no 24 de 01/08/94 da Secretaria de Agricultura e Abastecimento de Estado de São Paulo, para leite integral pasteurizado que é de $15-18^{\circ}$ Dornic. A média para acidez titulável para o leite crú e o tratamento por 5 minutos foi de $15^{\circ}$ Dornic e para os tratamentos por 10 e 15 minutos foram de $17^{\circ}$ Dornic.

Dos trabalhos revisados, nenhum estudo semelhante à este relata alteração importante da acidez do leite de vaca tratado por microondas.

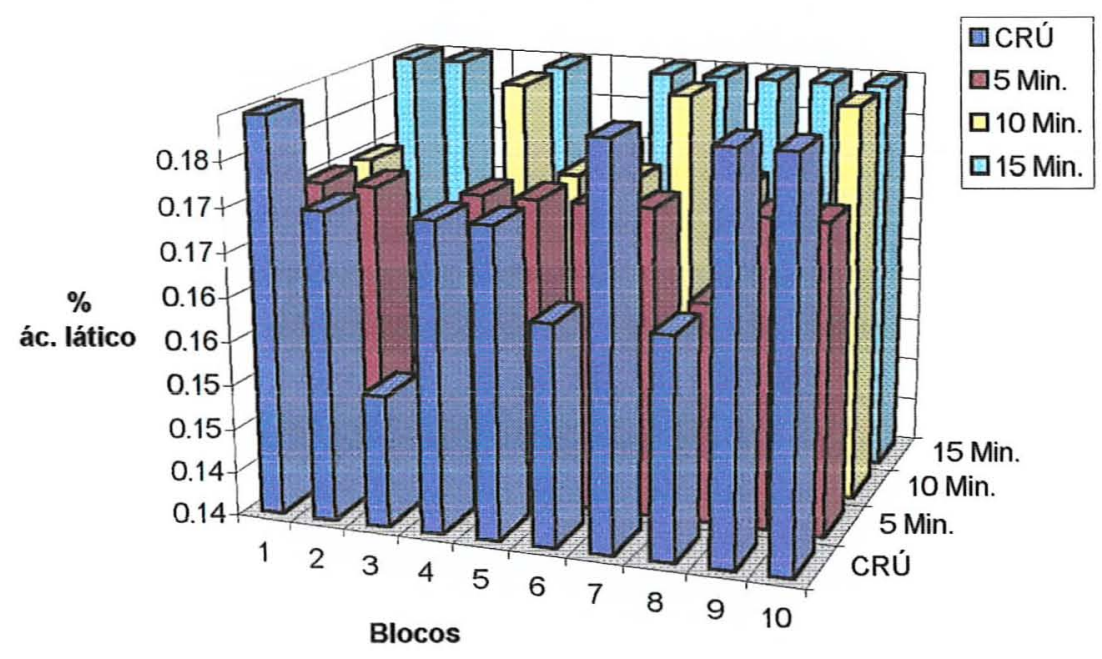

Figura 2. Ação das microondas sobre a acidez do leite de vaca

\subsection{Efeito do tratamento sobre as bactérias totais}

A Figura 3 mostra a variação da contagem de bactérias totais no leite de vaca submetido à ação das microondas. 
Estatisticamente todos os tratamentos diferem da testemunha $(\mathrm{p} \leq 0.01)$. Por outro lado, os tratamentos por 10 e 15 minutos não diferem entre si (teste de Tukey).

Na Tabela 5 do Apêndice, pode-se observar a redução da contagem de bactérias totais com o tratamento das amostras com microondas por 5,10 e 15 minutos. Embora houvesse redução, o tratamento por 5 minutos não foi suficiente para reduzir a população bacteriana a níveis adequados para o consumo. Entretanto, com 10 e 15 minutos de tratamento, a redução da carga bacteriana foi quase total. Segundo a Resolução no 24 de 01/08/94 da Secretaria de Agricultura e Abastecimento de Estado de São Paulo, o número máximo de células/ml permitido para leite cru é de $5 \times 10^{5}$ e $4 \times 10^{4}$ cels $/ \mathrm{ml}$ para leite pasteurizado As médias encontradas foram de $1.37 \times 10^{5}$ cels $/ \mathrm{ml}$ para o leite crú e $6.49 \times 10^{4}$, $4.64 \times 10^{1}$ e $2.85 \mathrm{cels} / \mathrm{ml}$ para os tratamentos por 5,10 e 15 minutos, respectivamente.

MERIN e ROSENTHAL (1984) ${ }^{11}$ citado por CALVO e OLANO (1992), observaram diminuição do número de microrganismos patogênicos ao comparar o efeito das microondas (700W e $2450 \mathrm{Mhz}$ ) aos tratamentos convencionais de leite. HAMID et al (1969) ${ }^{12}$ citado por KNUTSON et al (1987), ao tratar o leite de vaca por um método contínuo, considerou-o tão eficiente quanto em banho maria $(99.99 \%$ de redução em 10 e 12 segundos de exposição à 74.4 e $79.4^{\circ} \mathrm{C}$ ). JAYNES (1975), após método contínuo de exposição do leite de vaca às microondas $(2450 \mathrm{Mhz})$, observou redução da contagem de bactérias totais. THOMPSON e THOMPSON (1990) ao tratar leite de cabra por

\footnotetext{
${ }^{11}$ MERIN. R. : ROSENTHAL. I. Pasteurization of milk by microwave radiation. Milchwissenschalf. Nurnberg. 39(11): 643-4. 1984. apud CALVO. M. M.: OLANO. A. Thermal treatments of goat's milk. Ciência y Tecnologia de Alimentos. Valência. 32(2): 139-52, 1992.

${ }^{12}$ HAMID. M. A. K. et al. Microwave pasteurization of raw milk. Journal of Microwave Power. Ottawa. 4: 272-5. 1969. apud KNUTSON. K. M. et al. Microwave heating of food. Lebensmittel Wissenschaft und Technologie. London. 20(3): 101-10. 1987.
} 
microondas sob condições semelhantes, observaram diminuição da contagem de bactérias totais, sem alteração organoléptica.

Quanto às vantagens da utilização das microondas para o tratamento do leite MUDGETT e SCHWARTZBERG (1982) ressaltam o alcance de temperaturas centrais suficientemente alta para destruir microrganismos em alimentos fluidos, havendo, segundo EL-SHIBINY et al (1982) ${ }^{13}$ citado por KNUTSON et al (1987), uma relação ascendente da redução da contagem de bactérias com o aumento da temperatura.

Nos estudos que avaliaram a inativação das bactérias psicrotróficas, suas concentrações encontraram-se também diminuídas, tanto quando expostas à ação das microondas inoculadas em caldo nutriente (CUNNINGHAM, 1980), quanto quando avaliadas no leite refrigerado previamente submetido às microondas (MERIN e ROSENTHAL, $1984^{14}$ citado por CALVO e OLANO, 1992; CHIU et al, $1984^{15}$ citado por KNUTSON et al, 1987). SIMS et al (1991) observaram um aumento do tempo de vida útil do leite pela diminuição de psicotróficas e contagem de bactérias total do leite submetido às microondas DEIBEL et al (sdp) ${ }^{16}$ citado por KNUTSON et al (1987) relatam diminuição na concentração de C.jejuni em leite inoculado tratado por microondas.

\footnotetext{
${ }^{13}$ EL-SHIBINY. S. et al. Effect of microwaves on buffalo's milk. Egyptian Journal of Dairy Science. Cairo, 10: 29-34, 1982. apud KNUTSON, K. M. et al. Microwave heating of food. Lebensmittel Wissenschaft und Technologie, London, 20(3): 101-10, 1987.

${ }^{14}$ MERIN. R. : ROSENTHAL. I. Pasteurization of milk by microwave radiation. Milchwissenschalf. Nurnberg. 39(11): 643-4. 1984. apud CALVO. M. M.: OLANO. A. Thermal treatments of goat's milk. Ciência y Tecnologia de Alimentos. Valência. 32(2): 139-52. 1992.

${ }^{15}$ CHIU. C. P. et al. Microwave treatment of pasteurized milk. Journal of Microwave Power. Ottawa. 19: 269-72. 1984. apud KNUTSON. K. M. et al. Microwave heating of food. Lebensmittel Wissenschaft und Technologie. London. 20(3): 101-10. 1987.

${ }^{16}$ DEIBEL. K. E. et al. Destruction of Campvlobacter jejuni by microwave heating. Unpublished data. Department of Food Science and Nutrition. The Ohio State University. Colombus. OH. apud KNUTSON. K. M. et al. Microwave heating of food. Lebensmittel Wissenschaft und Technologie. London, 20(3): 101-10. 1987.
} 


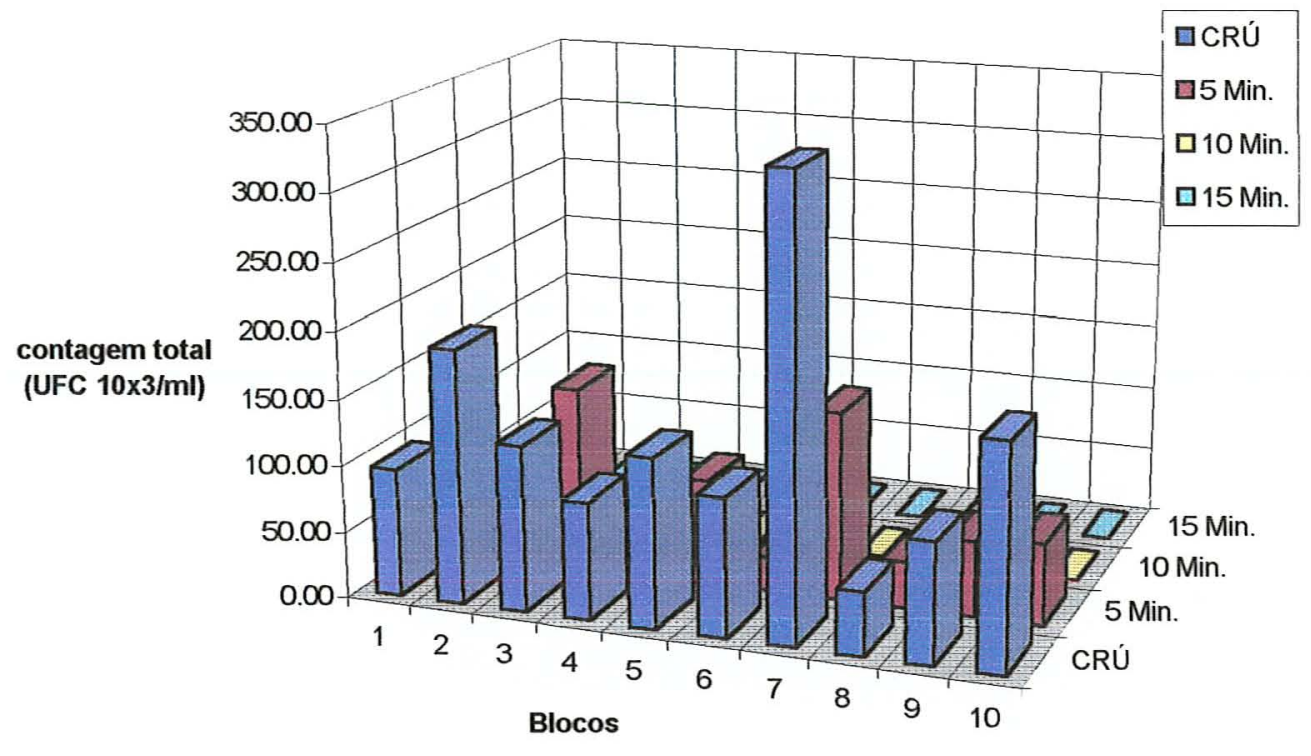

Figura 3. Ação das microondas sobre o número total de bactérias do leite de vaca

Considerando que, no presente trabalho, não ocorreu diferença estatisticamente significativa entre os tratamentos de 10 e 15 minutos, e que com 10 minutos o número de bactérias sobreviventes é nulo estando dentro dos padrões máximos estabelecidos pela Secretaria de Agricultura e Abastecimento (máximo de $5 \times 10^{5}$ cels $/ \mathrm{ml}$ ), não haverá necessidade em se aplicar um tratamento por 15 minutos para se assegurar que o produto estará dentro dos padrões legais para contagem de bactérias totais. As médias obtidas para o leite cru e para os tratamentos por 5,10 e 15 minutos foram, respectivamente, $1.37 \times 10^{5}, 6.49 \times 10^{4}$, $4.64 \times 10^{1}$ e $2.85 \mathrm{cels} / \mathrm{ml}$. 


\subsection{Efeito do tratamento sobre os coliformes totais}

O efeito das microondas sobre os coliformes totais é demonstrado na Figura 4 e na Tabela 6 do Apêndice.

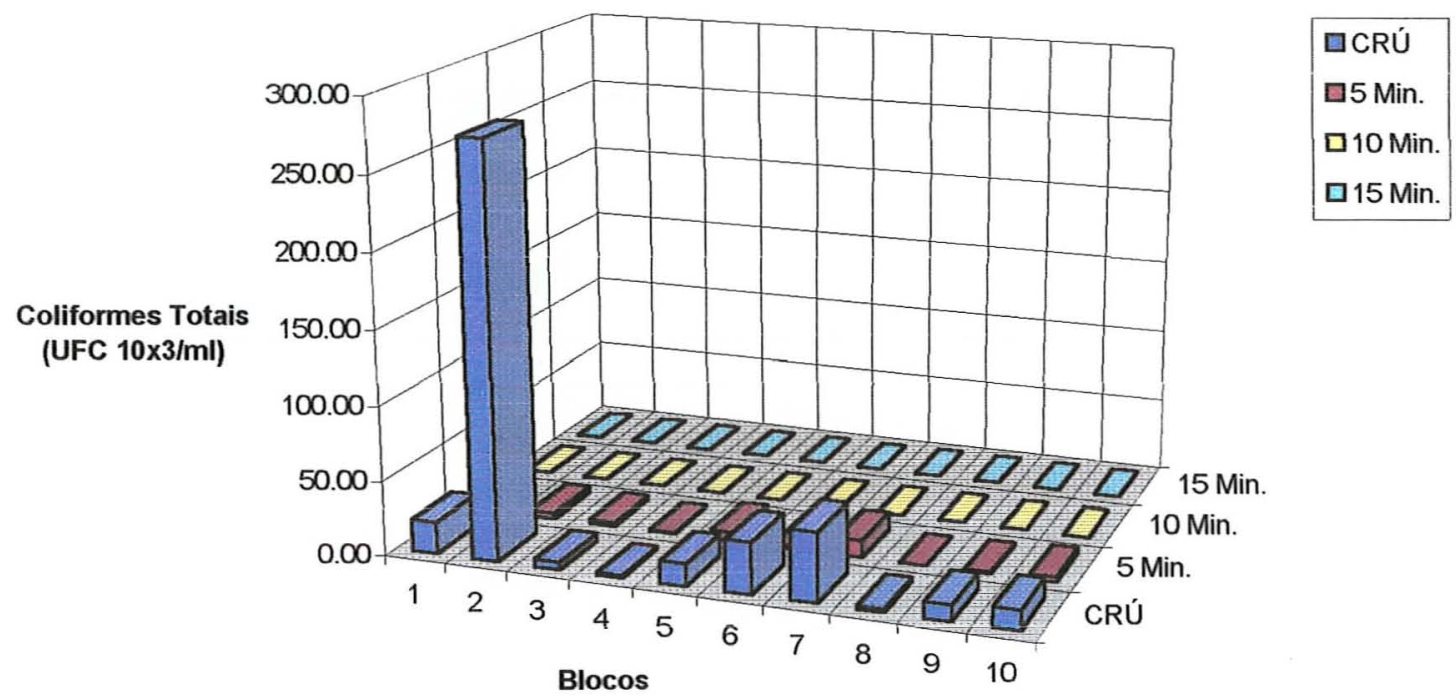

Figura 4. Ação das microondas sobre o número total de coliformes do leite de vaca

Pelos dados da Tabela 6, pode-se verificar que o tratamento por 5 minutos provoca uma redução na população de coliformes totais (média de $1.49 \times 10^{3}$ para a partir de contagem inicial de $4.95 \times 10^{3}$ ), sem alcançar entretanto segurança do ponto de vista da presença de patogênicos no alimento, uma vez que a Secretaria de Agricultura e Abastecimento estabelece um máximo de 2 
coliformes/ml (padrões para leite pasteurizado). Por sua vez, os tratamentos de 10 e 15 minutos provocaram redução total desses microrganismos.

JAYNES (1975) ao tratar leite de vaca sob microondas observou redução drástica na contagem de coliformes, enquanto que nos estudos de ELSHIBINY et al (1982) ${ }^{17}$ citados por KNUTSON et al (1987), não houve crescimento de coliformes durante 4 dias à temperatura ambiente. MERIN e ROSENTHAL (1984) ${ }^{18}$ citado por CALVO e OLANO (1992), relatam semelhança do tratamento com microondas e pasteurização por $30^{\prime}$ à $63^{\circ} \mathrm{C}$, sem deteç̧ão de coliformes. Segundo KNUTSON et al (1988), a persistência microbiológica no leite inoculado acontece apenas se o calor for desuniforme, o que pode facilmente ser revertido se o alimento, ao ser submetido às microondas seja manualmente misturado (por agitação ou batimento) para obter uma temperatura uniforme e então uma exposição dos microrganismos ao calor através do alimento.

No presente trabalho ficou demonstrado a possibilidade da utilização do forno microondas caseiro na redução da microbiota do leite (bactérias totais e coliformes totais), entretanto deve ser ressaltado que, em tratamentos por tempo superior a 10 minutos, cuidados devem ser tomados para que não haja transbordamento.

\footnotetext{
"EL-SHIBINY. S. et al. Effect of microwaves on buffalo's milk. Egyptian Journal of Dairy Science. Cairo. 10:29-34. 1982. apud KNUTSON. K. M. et al. Microwave heating of food. Lebensmittel Wissenschaft und Technologie. London. 20(3): 101-10. 1987.

${ }^{18}$ MERIN. R. : ROSENTHAL. I. Pasteurization of milk by microwave radiation. Milchwissenschalf. Nurnberg. 39(11): 6434.1984 . apud CALVO. M. M.: OLANO. A. Thermal treatments of goat s milk. Ciência y Tecnologia de Alimentos. Valência. 32(2): 139-52. 1992.
} 


\section{CONCLUSÕES}

A análise dos dados do tratamento do leite de vaca em forno de microondas caseiro leva às seguintes conclusões:

6.1. A aplicação de microondas para o tratamento do leite, visando inativação da carga microbiana, não afetou as características fisico químicas do mesmo.

6.2. O tratamento por 5 minutos, nas condições estudadas, embora provoque redução na população de bactérias totais $\mathrm{e}$ coliformes totais, não é suficiente para assegurar que o produto satisfaça os padrões microbiológicos legais.

6.3. A aplicação das microondas por 10 minutos ou mais é efetivo na redução do número de bactérias totais e coliformes totais à níveis compatíveis com a legislação vigente.

6.4. O tratamento por 10 minutos ou mais apresenta efeitos semelhantes à pasteurização sobre as bactérias totais $\mathrm{e}$ coliformes do leite de vaca nas condições estudadas. 
6.5. A partir de 10 minutos de tratamento do leite de vaca cru em microondas caseiro, com potência máxima, já se pode conseguir redução da população bacteriana total e de coliformes totais, correspondente àquela da pasteurização convencional. 


\section{REFERÊNCIAS BIBLIOGRÁFICAS}

AKTAS, S.N. \& OZILGEN, M. Injury of E.coli and degradation of riboflavin during pasteurization with microwaves in a tubular fow reactor. Lebensmittil-Wissenschaft \& Technologie, London, 25(5): 422-5, 1992.

CALVO, M.M. \& OLANO, A. Thermal treatments of goat's milk. Ciência $\mathbf{y}$ Tecnologia de Alimentos, Valencia, 32(2): 139-52, 1992.

CHOI, H.K.; VASAVADA, P.C. \& MARTH, E.H. Inactivation of milkborne pathogens with microwave energy. Journal of Dairy Science, Champaign, 75(Suppl 1): 1430, 1992.

CHOI, H.K.; MARTH, E.H. \& VASAVADA, P.C. Use of microwave energy to inactive Yersinia enterocolitica and Campylobacter jejuni in milk. Milchwissenschaft, Nurnberg, 48(3): 134-6, 1993. Apud. Dairy Science Abstracts, Wallingford, 55(7): 535, July 1993. (Resumo)

CHOI, H.K.; MARTH, E.H. \& VASAVADA, P.C. Use of microwave energy to inactivate Listeria monocytogenes in milk. Milchwissenschaft, Nurnberg, 48(4): 200-3, 1993. Apud. Dairy Science Abstracts, Wallingford, 55(8): 615, Aug 1993. (Resumo) 
CUNNINGHAM, F.E. Influence of microwave radiation on psychrotrophic bacteria, Journal of Food Protection, Ames, 43(8): 651-5, 1980.

FAY, L.; RICHLI, U. \& LIARDON, R. Evidence for the absence of amino acid isomerization in microwave-heated milk and infant formulas. Journal of Agricultural and Food Chemistry, Washington, 39(10): 1857-9, 1991.

FUNG, D.Y.C. \& CUNNINGHAM, F.E. Effect of microwaves on microorganisms in foods. Journal of Food Protection, Ames, 43(8): 641$50,1980$.

HEDDLESON, R.A.; DOORES, S. \& ANANTHESWARAN, R.C. Parameters affecting destruction of Salmonella spp by microwave heating. Journal of Food Science, Champaign, 59(2): 447-51, 1994.

JAYNES, H.O. Microwave pasteurization of milk. Journal of Dairy Science, Champaign, 57(1): 139, 1974.

JAYNES, H.O. Microwave pasteurization of milk. Journal of milk and Food Technology, Orange, 38(7), 1975.

KNUTSON, K.M.; MARTH, E.H. \& WAGNER, M.K. Microwave heating of food. Lebensmittel Wissenschaft und Technologie, London, 20(3): 101-10, 1987.

KNUTSON, K.M.; MARTH, E.H. \& WAGNER, M.K. Use of microwave ovens to pasteurize milk. Journal of Food Protection, Ames, 51(9): 715-9, 1988. 
KUDRA, T.; VAN DE VOORT, F.R.; RAGHAVAN, G.S.V. \& RAMASWAMY, H.S. Heating characteristcs of milk constituints in a microwave pasteurization system. Journal of Food Science, Champaigon, 56(4): 931-7, 1991.

MUDGETT, R.E. \& SCHWARTZBERG, H.G. Microwave food processing: pasteurization and sterilization. AIChE- Symposium Series, New York, 78(218): 1-11, 1982.

STANDARD Methods of the Examination of Products. In: RICHARDSON, G.H. American Public Health Association, Washington, 15 edições, 1985. 412p.

SÃO PAULO (Estado). - Secretaria de Agricultura e Abastecimento. Resolução 24, de 01/08/94. Diário Oficial do Estado; Seção I, São Paulo, 2 ago. 1994. p23.

SALE, A.J.H. A review of microwaves for food processing. Journal of Food Technology, London, 11(4): 319-29, 1976.

SIMS, L.A.; VASAVADA, P.C.; HULL, R.R.; CHANDLER, R.A. \& MARTH, E.H.. Impedimetric analysis of quality and shelf life of milk pasteurized by a continuous microwave treatment. Journal of Dairy Science, Champaign, 74(suppl): 139, 1991.

STEARNS, G.; VASAVADA, P.C. Effect of microwave processing on quality of milk. Journal of Food Protection, Ames, 49(10): 853, 1986. 
TEJERA, I.F.; HARDISSON de la TORRE, A. Procedimientos de conservacion de los alimentos. II-El calor. Alimentaria, Budapeste, 28: 21-6, 1991.

THOMPSON, J.S.; THOMPSON, A. In home pasteurization of raw goat's milk by microwave treatment. International Journal of Food Microbiology, Amsterdam, 10: 59-64, 1990.

VASAVADA, P.C. Microwave processing for the dairy industry. Food Australia, North Sydney, 42(12): 562-64, 1990.

VILLAMIEL, M. et al. Effects of continuous flow microwave treatment on chemical and microbiological characteristics of milk. $\mathbf{Z}$ Lebensm Unters Forsch, Kusnacht, 202: 15-8, 1996.

YOUNG, G.S.; JOLLY, P.G. Microwaves: the potencial for use in dairy. The Australian Journal of Dairy Technology, Melbourne, 45(5): 34-7, 1990. 
APÊNDICE 
Tabela 1. Composição de meio seletivo Bacto Violet Red Bile Agar (VRBA DIFCO) para determinação de bactérias coliformes em produtos lácteos, conforme o "STANDARD Methods for the Examination of Dairy Products".

$\begin{array}{lr}\text { Extrato de levedura } & 3.0 \mathrm{~g} \\ \text { Peptona } & 7.0 \mathrm{~g} \\ \text { Sais de Bilis } \mathrm{n}^{\circ} 3 & 1.5 \mathrm{~g} \\ \text { Lactose } & 10.0 \mathrm{~g} \\ \text { Cloreto de Sódio } & 5.0 \mathrm{~g} \\ \text { Ágar } & 15.0 \mathrm{~g} \\ \text { Roxo Neutro } & 0.03 \mathrm{~g} \\ \text { Cristal Violeta } & 0.002 \mathrm{~g} \\ \text { Para reidratar, suspender } 41,5 \mathrm{~g} \text { em } 1000 \mathrm{ml} \text { de água } \\ \text { destilada e aquecer até ferver. Deixar esfriar até } 45^{\circ} \mathrm{C} \\ \text { e dispensar nas placas }\end{array}$

Tabela 2. Composição de meio PCA para determinação do número total de bactérias em produtos lácteos, conforme o "STANDARD Methods for the Examination of Dairy Products".

Extrato de levedura

$2.5 \mathrm{~g}$

Triptona

$5.0 \mathrm{~g}$

Dextrose

$1.0 \mathrm{~g}$

Ágar

$15.0 \mathrm{~g}$

Para reidratar, suspender as quantidades designadas

em $1000 \mathrm{ml}$ de água destilada e esterilizar em autoclave. Deixar esfriar até $45^{\circ} \mathrm{C}$ e dispensar nas placas 
Tabela 3. Variação do pH do leite de vaca submetido à ação de microondas

\begin{tabular}{|c|c|c|c|c|}
\hline & CRU & 5 Min. & 10 Min. & 15 Min. \\
\hline \hline 1 & 6.67 & 6.68 & 6.66 & 6.66 \\
\hline 2 & 6.68 & 6.65 & 6.64 & 6.64 \\
\hline 3 & 6.70 & 6.70 & 6.68 & 6.63 \\
\hline 4 & 6.75 & 6.70 & 6.65 & 6.64 \\
\hline 5 & 6.74 & 6.73 & 6.69 & 6.67 \\
\hline 6 & 6.75 & 6.74 & 6.70 & 6.68 \\
\hline 7 & 6.69 & 6.67 & 6.64 & 6.63 \\
\hline 8 & 6.67 & 6.65 & 6.60 & 6.60 \\
\hline 9 & 6.66 & 6.65 & 6.63 & 6.60 \\
\hline 10 & 6.69 & 6.68 & 6.64 & 6.63 \\
\hline Média & 6.69 & 6.68 & 6.65 & 6.63 \\
\hline
\end{tabular}

Tabela 4. Variação da acidez do leite de vaca submetido à ação de microondas

\begin{tabular}{|c|c|c|c|c|}
\hline & CRU & 5 Min. & 10 Min. & 15 Min. \\
\hline \hline 1 & 0.18 & 0.17 & 0.17 & 0.18 \\
\hline 2 & 0.17 & 0.17 & 0.16 & 0.18 \\
\hline 3 & 0.15 & 0.15 & 0.16 & 0.16 \\
\hline 4 & 0.17 & 0.17 & 0.18 & 0.18 \\
\hline 5 & 0.17 & 0.17 & 0.17 & 0.17 \\
\hline 6 & 0.16 & 0.17 & 0.17 & 0.18 \\
\hline 7 & 0.18 & 0.17 & 0.18 & 0.18 \\
\hline 8 & 0.16 & 0.16 & 0.17 & 0.18 \\
\hline 9 & 0.18 & 0.17 & 0.17 & 0.18 \\
\hline 10 & 0.18 & 0.17 & 0.18 & 0.18 \\
\hline Média & 0.16 & 0.16 & 0.17 & 0.17 \\
\hline
\end{tabular}


Tabela 5. Variação do número total de bactérias do leite de vaca submetido à ação de microondas

\begin{tabular}{|c|c|c|c|c|}
\hline & CRU & 5 Min. & 10 Min. & 15 Min. \\
\hline \hline 1 & $9.6 \times 10^{4}$ & $2.93 \times 10^{4}$ & 4 & 1 \\
\hline 2 & $1.9 \times 10^{5}$ & $5.0 \times 10^{4}$ & $36 \times 10^{1}$ & 0 \\
\hline 3 & $1.24 \times 10^{5}$ & $1.38 \times 10^{5}$ & 5 & 2 \\
\hline 4 & $8.8 \times 10^{4}$ & $3.0 \times 10^{4}$ & 6 & 3 \\
\hline 5 & $1.26 \times 10^{5}$ & $7.9 \times 10^{4}$ & $4.3 \times 10^{1}$ & 4 \\
\hline 6 & $1.03 \times 10^{5}$ & $2.6 \times 10^{4}$ & $1.2 \times 10^{1}$ & 5 \\
\hline 7 & $3.39 \times 10^{5}$ & $1.42 \times 10^{5}$ & $1.0 \times 10^{1}$ & 3 \\
\hline 8 & $4.75 \times 10^{4}$ & $3.55 \times 10^{4}$ & 5 & 7 \\
\hline 9 & $9.0 \times 10^{4}$ & $5.7 \times 10^{4}$ & $1.0 \times 10^{4}$ & 3 \\
\hline 10 & $1.66 .10^{5}$ & $6.15 \times 10^{4}$ & 9 & 0 \\
\hline Média & $1.37 \times 10^{5}$ & $6.49 \times 10^{4}$ & $4.64 \times 10^{1}$ & 2.85 \\
\hline
\end{tabular}

Tabela 6 -Variação do número de coliformes do leite de vaca submetido à ação de microondas

\begin{tabular}{|c|c|c|c|c|}
\hline & CRU & 5 Min. & 10 Min. & 15 Min. \\
\hline 1 & $2.14 \times 10^{4}$ & $1.70 \times 10^{2}$ & 0 & 0 \\
\hline 2 & $2.75 \times 10^{5}$ & $3.82 \times 10^{3}$ & 0 & 0 \\
\hline 3 & $5.00 \times 10^{3}$ & $2.50 \times 10^{3}$ & 0 & 0 \\
\hline 4 & $1.38 \times 10^{3}$ & $5.30 \times 10^{2}$ & 0 & 0 \\
\hline 5 & $1.50 \times 10^{4}$ & $6.00 \times 10^{3}$ & 0 & 0 \\
\hline 6 & $3.45 \times 10^{4}$ & $2.20 \times 10^{3}$ & 0 & 0 \\
\hline 7 & $4.65 \times 10^{4}$ & $1.14 \times 10^{4}$ & 0 & 0 \\
\hline 8 & $2.25 \times 10^{3}$ & $6.00 \times 10^{4}$ & 0 & 0 \\
\hline 9 & $1.05 \times 10^{4}$ & $1.00 \times 10^{3}$ & 0 & 0 \\
\hline 10 & $1.30 \times 10^{4}$ & $3.10 \times 10^{3}$ & 0 & 0 \\
\hline Média & $4.95 \times 10^{3}$ & $1.49 \times 10^{3}$ & 0 & 0 \\
\hline
\end{tabular}


Tabela 7 -Variação da teperatura nos diferentes tempos e intervalos de tratamento

\begin{tabular}{|c|c|}
\hline TEMPO (Minutos) & TEMPERATURA $\left({ }^{\circ} \mathrm{C}\right)$ \\
\hline 2.5 & 32 \\
\hline 5.0 & 53 \\
\hline 7.5 & 71 \\
\hline 10.0 & 84 \\
\hline 12.5 & 93 \\
\hline 15.0 & 93 \\
\hline
\end{tabular}

